\title{
Pengaruh Implementasi Pengendalian Intern, Pemanfaatan Teknologi Informasi, dan Total Quality management Terhadap Penerapan Good Governance di Lembaga Amil Zakat
}

\author{
ERNI SURYANDARI F* \\ Program Studi Akuntansi Universitas Muhammadiyah Yogyakarta, Jl. Lingkar Selatan, Tamantirto, Kasihan, Bantul, D.I. Yogyakarta, 55183, Telp \\ +274 387656, Indonesia. \\ ${ }^{*}$ Corresponding Author, E-Mail Address: ErniSF@yahoo.com
}

\begin{abstract}
The purpose of the research is to know the effect of intern controlling implementation, the utilize of information technology and total quality management on good governance application on amil zakat institution. The participants on this research are the employee of amil zakat institution which is located in Yogyakarta. The technique of data collecting is by spreading the questioners. The amount of questioners is 100 questioner. This research uses Partial Least Square (PLS) as the analysis tool because the data that can be processed are only 42 questioners. Based on analysis which had been done by the researcher, it can be concluded that intern controlling implementation., the utilize of information technology, and total quality management give the positive and significant effect on good governance application with the value of $51,6 \%$ and the rest of it is from the variable outside of this research. The most effect variable on good governance apllication is the utilize of information technology.

Keywords: Intern Controlling,; Information Technology; Total Quality Management;Good Governance.
\end{abstract}

\section{ABSTRAK}

Tujuan dari penelitian ini adalah untuk mengetahui pengaruh penerapan pengendalian intern, Pemanfaatan teknologi informasi dan jumlah manajemen mutu pada aplikasi tata pemerintahan yang baik di lembaga amil zakat. Para peserta dalam penelitian ini adalah karyawan lembaga amil zakat yang terletak di Yogyakarta. Teknik pengumpulan data adalah dengan menyebarkan kuesioner. Jumlah kuesioner adalah 100 kuesioner. Penelitian ini menggunakan Partial Least Square (PLS) sebagai alat analisis karena data yang dapat diproses hanya 42 kuesioner. Berdasarkan analisis yang telah dilakukan oleh peneliti, dapat disimpulkan bahwa magang mengendalikan pelaksanaan., Yang memanfaatkan teknologi informasi, dan manajemen kualitas total memberikan efek positif dan signifikan pada aplikasi tata pemerintahan yang baik dengan nilai 51,6\% dan sisanya adalah dari luar variabel penelitian ini. Yang paling berpengaruh variabel pada apllication tata pemerintahan yang baik adalah memanfaatkan teknologi informasi.

Kata Kunci:Pengendalian Intern;Teknologi Informasi;Manajemen Kualitas Menyeluruh;Tata Kelola Yang Baik.

\section{PENDAHULUAN}

Zakat adalah harta yang dikeluarkan oleh umat muslim ketika nizabnya telah terpenuhi. Indonesia memiliki potensi zakat yang sangat besar, hal ini dilihat dari $80 \%$ penduduk Indonesia adalah umat Islam. Hingga tahun 2012 potensi zakat di Indonesia bisa mencapai Rp 300 T namun sampai saat ini hanya terkumpul sebesar Rp 1,8 T. Hal ini terjadi karena kurangnya kesadaran perusahaanperusahaan besar serta masyarakat dalam membayar zakat. Zakat di Indonesia telah di atur dalam UU no 38 tahun 1999 dan mengalami pembaharuan menjadi UU no 23 tahun 2011. Perbedaan UU dalam pengelolaan zakat banyak mendapat kritik dan protes dari berbagai pihak karena banyaknya celah berbahaya dalam UU terbaru ini maka menjadi tugas seluruh pihak untuk bekerja keras dalam mengawal UU.

Di sisilain, berdirinya Lembaga Amil Zakat 
(LAZ) yang semakin banyak dan diperbaharuinnya UU belum disertai dengan minat masyarakat membayar zakat pada LAZ yang berdampak belum optimalnya penge-lolaan zakat. Masyarakat beranggapan bahwa LAZ masih belum profesional karena belum menerapkan akuntabilitas dan transparansi, LAZ belum memiliki SDM yang optimal, dan sistem birokrasi dan good gavernance yang masih lemah.

Permasalahan yang kompleks ini berawal dari ketidakpercayaan masya164

rakat terhadap LAZ dan kurangnya sosialisasi serta informasi mengenai LAZ tersebut. Untuk menjawab permasalahan tersebut perlu diciptakan pengelolaan $\mathrm{LAZ}$ yang baik atau yang sering disebut good governance. Untuk mencapai tata kelola yang baik satu pilar yang harus diterapkan adalah pengendalian intern (PI), selanjutnya satu model yaitu Total Quality Management (TQM) dan dilengkapi dengan pemanfaatan teknologi informasi. Alasan PI diterapkan adalah membantu agar organisasi dapat mencapai tujuan dengan efisien. Selanjutnya untuk melengkapi penerapan PI, model yang juga sebaiknya diterapkan adalah TQM. Alasan perlu diterapkan TQM dalam LAZ adalah bertujuan untuk memperbaiki mutu dari semua aspek yang terdapat dalam LAZ agar penerapan GG terlaksana secara maksimal.

Pemanfaatan teknologi informasi juga saat penting dalam LAZ. Informasi tersebut harus bermanfaat bagi para pemakai sama dengan mengatakan bahwa informasi harus mempunyai nilai (Suwardjono, 2005; Winidyaningrum dan Rahmawati, 2010). Informasi akan bermanfaat kalau informasi tersebut dipahami dan digunakan oleh pemakai dan juga bermanfaat kalau pemakai mempercayai informasi tersebut. (Winidyaningrum dan Rahmawati, 2010).

Berdasarkan latar belakang inilah peneliti memilih penelitian dengan tujuan untuk mengetahui lebih lanjut dan sejauh mana implementasi PI, pemanfaatan TI, dan implementasi TQM berpengaruh terhadap penerapan GG pada LAZ. Hasil dari penelitian ini diharapkan dapat memberikan kontribusi praktis agar LAZ dapat menjalankan praktik tata kelola yang baik, yang selanjutnya mampu menciptakan kepercayaan oleh masyarakat kepada lembaga LAZ tersebut. Dari sisi teoritis, hasil penelitian ini diharapkan memberikan kontribusi dalam pengembangan konsep good governance di lembaga publik.

\section{TINJAUAN LITERATUR DAN PERUMUSAN HIPOTESIS}

\section{PENGENDALIAN INTERN}

Pengertian pengendalian intern menurut Committee Of Sponsoring Organization of The Treadway Commission (COSO) yang dikutip oleh Elrafa menyebutkan bahwa pengendalian intern adalah suatu proses, yang dipengaruhi oleh dewan komisaris, manajemen, dan personil lainnya dari sebuah entitas, yang dirancang untuk memberikan keyakinan/jaminan yang wajar berkaitan dengan pencapaian tujuan dalamkategori efektivitas dan efisiensi operasi, keandalan laporan keuangan dan kepatuhan terhadap hukum dan peraturan yang berlaku.

Menurut COSO komponen PI, meliputi: (1) Ling-kungan pengendalian (control environ-ment); (2) Penaksiran risiko (risk assessment); (3) Aktivitas pengendalian (control activity); (4) Informasi dan komunikasi (information and commu-nication); dan (5) Pemantauan (monitoring) (lihat Fadillah, 2011).

\section{TEKNOLOGI INFORMASI}

Menurut Mc Keown (2001) dan Ahira (2010) teknologi informasi adalah seluruh bentuk teknologi yang digunakan untuk menciptakan, menyimpan, mengubah, dan untuk menggunakan 
informasi tersebut dalam segala bentuknya. Kemampuan untuk mengelola informasi secara efektif di dalam sebuah organisasi sangat penting karena dapat menjadi dasar untuk memperoleh keunggulan kompetitif, informasi telah menjadi aktiva tidak berwujud, yang jika dikelola dengan baik, dapat digunakan untuk meningkatkan sumber-sumber perusahaan lainnya (Zahra, 2009).

Tingkat ketergantungan organisasi dengan teknologi informasi semakin mening-kat, bahkan untuk sebagian organisasi teknologi informasi menjadi nyawa keberlangsungan organisasi atau perusahaan tersebut, maka dari itu untu164

$\mathrm{k}$ mencapai perusahaan yang good governance peran teknologi menjadi sangat penting untuk keberlangsungan perusahaan.

\section{TOTAL QUALITY MANAGEMENT}

Menurut International Organization for Standarization (ISO) (lihat Natha (2008) TQM adalah pendekatan manajemen pada suatu organisasi, berfokus pada kualitas dan didasarkan atas partisipasi dari keseluruhan sumber daya manusia dan ditujukan pada kesuksesan jangka panjang melalui kepuasan pelanggan dan memberikan manfaat pada anggota organisasi (sumber daya manusianya) dan masyarakat.

\section{Menurut Tenner dan Detoro (1992) TQM} memiliki tiga falsafah dasar yang dapat ditarik sebagai titik pertemuan dari berbagai pendapat tentang TQM, yakni: (1) Berfokus pada kepuasan pelanggan (Customer Focus); (2) Pemberdayaan dan Pelibatan Karyawan (Employee Empowerment and Invoivement); dan (3) Peningkatan kualitas secara berkelanjutan (continuous improvement) (Fadillah, 2011).

\section{GOOD GOVERNANCE}

Good governance adalah tata kelola yang baik pada suatu usaha yang dilandasi oleh etika profesional dalam berusaha/berkarya. Good Governance juga dimaksudkan sebagai suatu kemampuan manajerial untuk mengelola sumber daya dan urusan suatu negara dengan cara-cara terbuka, transparan, akuntabel, equitable, dan responsif terhadap kebutuhan masyarakat (Widyananda, 2008).

Dalam penerapan good governance diperlukan prinsip-prinsip yang dijadikan pedoman agar penerapan tersebut berjalan seperti yang diinginkan. Adapun prinsip-prinsip good governance menurut Putusan Bank Indonesia No,8/4/PBI/ 2006 dalam Umam (2009) yaitu: (a)

Pertanggungjawaban (Responsibility), (b) Pertanggungjelasan (Accountability), (c) Keadilan (Fairness), (d) Keterbukaan (Transparancy), (e) Kemandirian (Independency).

\section{Pengendalian Intern dan Good Governance}

Penelitian terdahulu yang dilakukan oleh Fadillah (2011) menemukan bahwa implementasi pengendalian intern berpenga-ruh secara langsung dan secara tidak langsung terhadap penerapan good governance. Secara riil jika Pengendalian Intern diterapkan pada LAZ dengan baik maka akan tercipta akuntabilitas dan transparansi yang maksimal untuk menuju pada tata kelola (good governance) yang baik pula. Dari uraian tersebut penurunan hipotesis pada penelitian ini yaitu:

$\mathrm{H}_{1}$ : Implementasi Pengendalian Intern berpengaruh positif terhadap pene-rapan Good Governance pada LAZ.

\section{TEKNOLOGI INFORMASI DAN GOOD GOVERNANCE}

Mulyadi (1997) mengatakan bahwa teknologi maju, khususnya teknologi informasi, akan menyebabkan perubahan radikal maupun berkelanjutan pada organisasi. Dengan aplikasi teknologi maka organisasi akan mengalami perubahan sistem manajemen, dari system tradisional ke sistem manajemen kontemporer. 
Penelitian Young et al. (2007) mene-mukan bahwa sistem/teknologi informasi yang dimiliki pemerintah daerah di kotamadya-kotamadya Yunani merupakan alat yang sangat berguna untuk menilai fungsionalitas sebuah sistem dan tingkat kesesuaian dengan lingkungan organisasional. Pemanfaatan informasi yang baik akan memperbaiki hubungan antara LAZ dengan masyarakat dan potensi zakat di Indonesia kemungkinan besar akan mengalami peningkatan.

Semakin baik pemanfaatan teknologi informasi LAZ maka penerapan good governance seharusnya juga semakin baik karena dengan memanfaatkan teknologi informasi maka akan lebih efektif dan efisien dalam segala hal yang berhubungan dengan aktivitas yang dilakukan dalam LAZ. Berdasarkan uraian diduga bahwa pemanfaatan teknologi informasi berpengaruh positif terhadap penerapan good governance. maka penurunan hipotesis dalam penelitian ini adalah :

$\mathrm{H}_{2}$ : Pemanfaatan teknologi informasi berpengaruh positif terhadap pene-rapan good governance pada LAZ.

\section{TOTAL QUALITY MANAGEMENT DAN GOOD GOVERNANCE}

Semakin baik penerapan total quality management maka semakin baik pula good governance pada LAZ karena dengan total quality management diterapkan maka LAZ akan lebih unggul dan dapat bersaing mendapatkan kepercayaan yang penuh dari masyarakat dan good governance juga akan semakin baik pula. Untuk mendukung penelitian terdahulu yang meyakini bahwa implementasi total qualty management berpengaruh secara signifikan terhadap penerapan good governance (Fadillah, 2011), penurunan hipotesis penelitian ini adalah :

$\mathrm{H}_{3}$ : Implementasi total quality management berpengaruh positif terhadap pene-rapan good governance pada LAZ.

\section{METODE PENELITIAN JENIS PENELITIAN}

Penelitian ini bersifat penjelasan (explanatory research) karena mejelaskan hubungan kausal di antara variabel-variabel. Pengujian explanatory mengacu pada teori atau hipotesis yang akan diuji sebagai penyebab terjadinya suatu fenomena. Objek penelitian kali ini adalah Lembaga Amil Zakat pada beberapa daerah. Dengan sampel adalah karyawan Lembaga Amil Zakat tersebut. Jenis data dalam penelitian ini adalah primer karena data yang dikumpulkan menggunakan kuisioner.

\section{SAMPEL}

Teknik pengumpulan sampel yang dipilih oleh penulis adalah random sampling. Teknik dimana populasi memiliki kesempatan yang sama untuk dijadikan sampel. Metode analisis data yang dilakukan pada penelitian ini adalah meliputi :

\section{UJ STATISTIK DESKRIPTIF}

Uji statistik deskriptif adalah uji yang memberi gambaran terhadap obyek yang diteliti melalui data sampel atau populasi sebagaimana adanya tanpa melakukan analisis dan membuat kesimpulan secara umum.

\section{UJI VALIDITAS}

Uji validitas yang dilakukan untuk mengetahui seberapa cermat suatu test (alat pengukur) melakukan fungsi ukurannya (Azwar, 1992). Uji validitas yang digunakan adalah uji validitas item, yaitu pengujian terhadap kualitas item-itemnya. Pengujian dilakukan dengan menggunakan Pearson Product Moment. Adapun data dikatakan valid apabila $r$ hitung lebih besar dari $r$ tabel pada taraf signifikansi .

\section{UJI REALIBILITAS}

Uji reabilitas dimaksudkan untuk mengetahui 


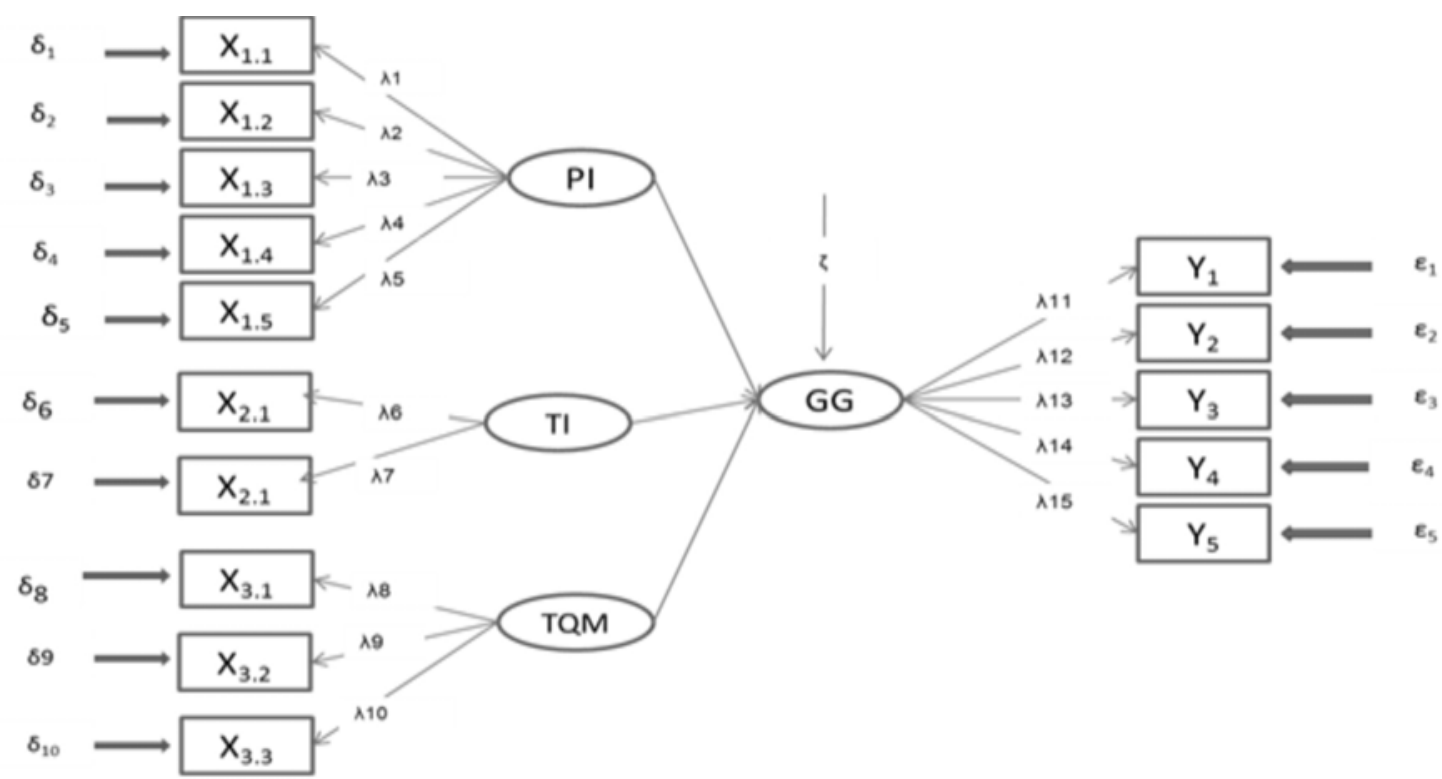

GAMBAR 1. DIAGRAM JALUR HUBUNGAN ANTAR VARIABEL PENELITIAN

sejauh mana hasil pengukuran terhadap konsisten, apabila dilakukan pengukuran dua kali atau lebih terhadap gejala yang sama dengan menggunakan alat pengukur yang sama. Teknik pengujian yang digunakan dalam penelitian ini adalah teknik analisa dengan menggunakan Cronbach's Alpha yang menunjukan realiabilitas, konsistensi internal dan homogenitas antar butir dalam variabel yang diteliti. Instrumen yang dipakai dalam variabel itu dikatakan handal apabila memiliki cronbach's alpha lebih dari 0.60 .

\section{UJ HIPOTESIS DAN ANALISIS DATA}

Metode analisis data yang digunakan dalam penelitian ini adalah menggunakan partial least square (PLS). PLS merupakan metode SEM berbasis varian yang didesain untuk menyelesaikan persoalan yang tidak dapat dilakukan oleh SEM seperti jumlah sampel kecil, data tidak terdistribusi normal secara multivariate, adanya missing values, dan adanya problem multikolonieritas.

Model analisis semua variabel laten dalam PLS terdiri dari tiga bentuk hubungan: (1) inner model yaitu model yang menspesifikasi hubungan antar variabel laten, atau dalam SEM disebut struktural model. (2) outer model yaitu model yang menspesifikasi hubungan antara variabel laten dengan indikatornya, atau dalam SEM disebut model pengukuran. (3) weight relation yang digunakan untuk mengestimasi variabel laten.

Pada penelitian ini partial least square (PLS) digunakan untuk mengetahui besarnya pengaruh secara parsial maupun simultan implementasi pengendalian intern, implementasi total quality management, dan pemanfaatan teknologi informasiterhadap penerapan good governance pada Lembaga Amil Zakat. Untuk menguji hipotesis diatas digunakan uji t dengan kriteria pengujian

TABEL 1. RINCIAN PENGIRIMAN DAN PENGEMBALIAN KUISIONER

\begin{tabular}{lll}
\hline Keterangan & Jumlah \\
\hline Kuisioner yang dikirim dengan rincian : & & \\
1) LazizMU Yogyakarta & 10 eksemplar \\
2) Rumah Zakat Yogyakarta & 10 eksemplar \\
3) Dompet Dhuafa Yogyakarta & 10 eksemplar \\
4)PKPU Yogyakarta & 10 eksemplar \\
5) DD Tauhid Yogyakarta & 10 eksemplar & 50 \\
& & \\
Kuisioner yang tidak kembali & & 8 \\
Kuisioner diolah & & 42 \\
\hline
\end{tabular}


"Hipotesis diterima jika t hitung lebih besar dari t tabel”.

\section{HASIL DAN PEMBAHASAN GAMBARAN UMUM OBYEK PENELITIAN}

Kelembagaan zakat di Indonesia diatur dalam Bab III UU Nomor 38 Tahun 1999, meliputi badan amil zakat dan lembaga amil zakat. Saat ini di Indonesia terdapat sekitar 17 lembaga amil zakat, infaq dan sedekah (Lazis) yang dikelola organisasi yang dibentuk masyarakat, di antaranya Dompet Dhuafa, Pos Keadilan Peduli Umat (PKPU), Rumah Zakat dan sejumlah lembaga amil zakat yang dikelola organisasi muslim seperti Nahdlatul Ulama dan Muhammadiyah.

\section{HASIL UJ KUALITAS INSTRUMEN}

Instrumen penelitian yang berupa butir-butir pertanyaan yang digunakan untuk mengukur variabel (kuisioner), perlu diuji validitas dan realibilitasnya untuk menjamin kualitas dari alat ukur tersebut. Pengujian dilakukan terhadap kuesioner yang telah diisi oleh responden dengan menggunakan alat bantu SPSS Versi19 for Windows adalah sebagai berikut.

\section{HASIL UJ VALIDITAS}

Instrumen dikatakan valid apabila $r$ hitung lebih besar dari $r$ tabel pada taraf signifikansi (a) $=5 \%$ (Sugiyono, 2005). Dengan jumlah sampel penelitian yang dapat diolah sebanyak 42 responden, maka dapat ditentukan besar $r$ tabel yaitu 0,304 . Hasil uji validitas pada variabel pengendalian intern $\left(\mathrm{X}_{1}\right)$, teknologi informasi $\left(\mathrm{X}_{2}\right)$, total quality management $\left(\mathrm{X}_{3}\right)$, dan good governance $(\mathrm{Y})$ dapat dilihat pada Lampiran.

Dari hasil uji validitas (lihat Lampiran) ditemukan bahwa seluruh butir pertanyaan pada variabel Pengendalian Intern $\left(\mathrm{X}_{1}\right)$, Teknologi Informasi $\left(\mathrm{X}_{2}\right)$, Total Quality Management $\left(\mathrm{X}_{3}\right)$, dan
Good Governance $(\mathrm{Y})$ memiliki nilai $\mathrm{r}$ hitung yang lebih besar dari $r$ tabel pada taraf signifikansi (a) $5 \%$, maka seluruh butir pertanyaan dinyatakan valid, sehingga seluruh butir pertanyaan dalam kuisioner layak digunakan sebagai instrumen untuk mengukur data penelitian.

\section{HASIL UJI RELIABILITAS}

Kuesioner dikatakan reliabel apabila kuesioner tersebut memberikan hasil yang konsisten jika digunakan secara berulang kali dengan asumsi kondisi pada saat pengukuran tidak berubah/obyek yang sama (Sugiyono, 2011). Pengujian reliabilitas dalam penelitian ini menggunakan Cronbach Alpha. Menurut Indriantoro dan Bambang (2002), suatu alat ukur disebut reliabel apabila memiliki Cronbach Alpha lebih besar dari 0,6. Hasil uji reliabilitaspada variabel pengendalian intern $\left(\mathrm{X}_{1}\right)$, teknologi informasi $\left(\mathrm{X}_{2}\right)$, total quality management $\left(\mathrm{X}_{3}\right)$, dan good governance(Y) dapat dilihat pada Tabel 3 di Lampiran. Hasil uji reliabilitas pada Tabel 3 di Lampiran memperlihatkan bahwa nilai Cronbach's Alpha pada semua variabel penelitian lebih besar dari 0,6, maka dapat dikatakan bahwa seluruh butir pertanyaan yang ada pada masing-masing variabel penelitian dalam kuisioner adalah reliabel atau handal, sehingga butir-butir pertanyaan tersebut dapat digunakan untuk penelitian selanjutnya.

\section{DESKRIPSI KARAKTERITIK RESPONDENI DENGAN JUMLAH KUISINER YANG LAYAK}

Data mengenai distribusi karakteristik responden sesuai dengan jumlahkuisioner yang layak dianalisis sebanyak 42 kuisioner dikelompokkan berdasarkan jenis kelamin dapat dilihat pada tabel 2 sampai 4 .

\section{JENIS KELAMIN}

Berdasarkan jenis kelamin responden, terdiri atas dua kelompok, yaitu kelompok laki-laki dan 
perempuan. Hasil analisis data jenis kelamin responden sesuai dengan perolehan data yang terkumpul melalui kuesioner, diperoleh 42 responden yang diambil sebagai sampel. Dari 42 responden tersebut mayoritas responden berjenis kelamin laki-laki yaitu sebanyak 24 orang atau sebesar $57,14 \%$ dan sisanya sebanyak 18 orang atau sebesar $42,86 \%$ adalah perempuan.

\section{HASIL ANALISIS DATA}

Pengujian Outer Model dan Pengujian Convergent Validity

Nilai factor loading masing-masing indikator dalam membentuk konstruk atau variabel pengendalian intern dapat dilihat pada Tabel 2 . Berdasarkan Tabel 2 dapat diketahui bahwa skor factor loading masing-masing indikator dari variabel pengendalian intern, Teknologi Informasi, total quality management, dan penerapan good governance lebih besar dari skor yang dipersyaratkan yaitu sebesar 0,50, yang berarti bahwa seluruh indikator sudah memenuhi asumsi convergent validity.

\section{Pengujian Discriminant Validity}

Hasil pengujian discriminant validity (lihat Tabel 3) menunjukkan bahwa skor akar kuadrat AVE dari variabel pengendalian intern $/ \mathrm{X}_{1}(0,736)$ lebih besar dari pada skor korelasi variabel atau konstruk pengendalian intern dengan konstruk good governance/Y $(0,302)$, skor akar kuadrat AVE dari variabel teknologi informasi/ $\mathrm{X}_{2}(0,862)$ lebih besar dari pada skor korelasi variabel teknologi informasi dengan konstruk good governance $(0,316)$, begitu juga dengan skor akar kuadrat AVE dari variabel total quality management $/ \mathrm{X}_{3}(0,851)$ lebih besar dari pada skor korelasi variabel atau konstruk total quality management dengan konstruk good governance/ $\mathrm{Y}$ $(0,195)$, sehingga dapat disimpulkan bahwa semua konstruk dalam model yang diestimasi memenuhi kriteria discriminant validity.
TABEL 2. FACTOR LOADING INDIKATOR VARIABEL

\begin{tabular}{lll}
\hline Keterangan & Jumlah \\
\hline $\begin{array}{l}\text { Kuisioner yang dikirim dengan rincian : } \\
\text { 1) LazizMU Yogyakarta }\end{array}$ & 10 eksemplar \\
2) Rumah Zakat Yogyakarta & 10 eksemplar \\
3) Dompet Dhuafa Yogyakarta & 10 eksemplar & \\
4)PKPU Yogyakarta & 10 eksemplar & \\
5)DD Tauhid Yogyakarta & 10 eksemplar & 50 \\
& & \\
Kuisioner yang tidak kembali & & 8 \\
Kuisioner diolah & & 42 \\
\hline
\end{tabular}

TABEL 3. HASIL UJ DISCRIMINANT VALIDITY

\begin{tabular}{lllll}
\hline Variabel & AVE & $\sqrt{\text { AVE }}$ & $\begin{array}{l}\text { Koefisien Korelasi } \\
\text { dengan variabel Y }\end{array}$ & Keterangan \\
\hline $\operatorname{PI}\left(X_{1}\right)$ & 0,541 & 0,736 & 0,302 & Diterima \\
$\operatorname{TI}\left(X_{2}\right)$ & 0,743 & 0,862 & 0,316 & Diterima \\
$\operatorname{TQM}\left(X_{3}\right)$ & 0,725 & 0,851 & 0,195 & Diterima \\
$R$ R Square $\left(R^{2}\right)$ & & & & 0,516 \\
\hline
\end{tabular}

TABEL 4. HASIL UJI RELIABILITAS KONSTRUK

\begin{tabular}{llll}
\hline KonstrukNVariabel & $\begin{array}{l}\text { Composite } \\
\text { Reliability }\end{array}$ & $\begin{array}{l}\text { Cronbach's } \\
\text { Alpha }\end{array}$ & Keterangan \\
\hline Pengendalian Intern $\left(X_{1}\right)$ & 0,850 & 0,776 & Reliabel \\
Teknologi Informasi $\left(X_{2}\right)$ & 0,852 & 0,656 & Reliabel \\
Total Quality Management $\left(X_{3}\right)$ & 0,887 & 0,811 & Reliabel \\
Good Governance $(Y)$ & 0,825 & 0,732 & Reliabel \\
\hline
\end{tabular}

TABEL 5. HASIL UJI INNER MODEL

\begin{tabular}{lllll}
\hline Jalur Pengaruh & Koefisien & $\dagger-$ hitung & $\dagger-$ tabel & Keterangan \\
\hline PI ---> GG & 0,302 & 2,583 & 1,686 & Signifikan \\
TI ---> GG & 0,316 & 2,568 & 1,686 & Signifikan \\
TQM ---> GG & 0,195 & 1,895 & 1,686 & Signifikan \\
\hline
\end{tabular}

\section{Pengujian Reliabilitas Konstruk}

Selain harus memenuhi uji validitas konstruk yang meliputi convergent validity serta discriminant validity, suatu konstruk juga harus memenuhi uji reliabilitas konstruk yang diukur dengan dua kriteria yaitu composite reliability dan cronbach's alpha 
dari blok indikator yang mengukur konstruk. Konstruk dinyatakan reliabel jika nilai atau skor composite reliability dan cronbachs alpha lebih besar dari 0,60. Hasil uji reliabilitas konstruk pada masing-masing variabel penelitian dapat dilihat pada Tabel 4. Berdasarkan hasil uji reliabilitas konstruk ditemukan bahwa seluruh variabel atau konstruk yang diteliti memiliki skor composite reliability dan cronbach's alpha lebih besar dari skor atau nilai yang dipersyaratkan yaitu 0,60. Hal tersebut dapat disimpulkan bahwa seluruh konstruk atau variabel yang diteliti memiliki reliabilitas yang baik atau dengan kata lain telah memenuhi uji reliabilitas konstruk.

\section{PENGUJIAN HIPOTESIS (INNER MODEL)}

Pengujian inner model bertujuan untuk membuktikan hipotesis yang telah diajukan dalam penelitian ini atau dengan kata lain pengujian inner model dilakukan untuk mengetahui pengaruh secara parsial dari seluruh konstruk laten eksogen (variabel independen/X) terhadap konstruk laten endogen (variabel dependen/Y). Hasil pengujian inner model dapat dilihat pada Tabel 5. Berdasarkan hasil uji inner model seperti terlihat pada Tabel 11 di Lampiran, maka dilihat bahwa variabel pengendalian intern mempunyai arah positif sebesar 0,302 terhadap variabel good governance dan pengaruhnya signifikan karena memiliki nilai thitung $(2,583)$ lebih besar dari nilai t tabel $(1,686)$, atau dengan kata lain pengendalian intern berpengaruh positif dan signifikan terhadap good governance. Hal tersebut berarti bahwa semakin baik pengendalian intern yang diimplementasikan oleh LAZ, maka semakin baik pula good governance-nya dan sebaliknya, sehingga dapat disimpulkan hipotesis satu $\left(\mathrm{H}_{1}\right)$ dalam penelitian ini terbukti/ diterima.

Variabel teknologi informasi mempunyai arah positif sebesar 0,316 terhadap variabel good gover- nance dan pengaruhnya signifikan karena memiliki nilai t-hitung $(2,568)$ lebih besar dari nilai t tabel $(1,686)$, atau dengan kata lain teknologi informasi berpengaruh positif dan signifikan terhadap good governance. Hal ini berarti bahwa semakin baik LAZ dalam menggunakan teknologi informasi akan berdampak pada semakin baiknya good governance, sehingga dapat disimpulkan hipotesis dua $\left(\mathrm{H}_{2}\right)$ dalam penelitian ini terbukti/diterima.

Sedangkan variabel total quality management mempunyai arah positif sebesar 0,195 terhadap variabel good governance dan pengaruhnya signifikan karena memiliki nilai t-hitung $(1,895)$ lebih besar dari nilai t tabel $(1,686)$, atau dengan kata lain total quality management berpengaruh positif dan signifikan terhadap good governance. Hal ini berarti semakin baik pelaksanaan total quality management oleh LAZ, maka cenderung berdampak pada semakin baiknya good governance,sehingga dapat disimpulkan hipotesis tiga $\left(\mathrm{H}_{3}\right)$ dalam penelitian ini terbukti/diterima.

\section{PENGUJIAN WEIGHT $\left(\mathrm{R}^{2}\right)$}

Pengujian Weight merupakan istilah lain dari uji koefisien determinasi pada analisis regresi berganda atau uji goodness-fit model pada analisis SEM. Hasil $\mathrm{R}^{2}$ pada dapat dilihat pada Tabel 6. Hasil Uji Wieght menemukan bahwa model yang dibangun, yakni pengaruh pengendalian intern, teknologi informasi, serta total quality management terhadap good governance memberikan nilai $\mathrm{R}^{2}$ sebesar 0,516 , yang dapat diinterpretasikan bahwa variabilitas konstruk good governance dapat dijelaskan oleh variabilitas konstruk pengendalian intern, teknologi informasi, serta total quality management sebesar 51,6\%, sedangkan sisanya 48,4\% dijelaskan oleh variabel atau konstruk lain diluar yang diteliti.

\section{SIMPULAN}

Berdasarkan hasil analisis data dan pem-bahasan 
mengenai pengaruh pengendalian intern, teknologi informasi, serta total quality management terhadap good governance, maka dapat diambil beberapa kesimpulan sebagai berikut. Implementasi pengendalian intern berpengaruh positif terhadap penerapan good governance pada LAZ. Semakin baik penerapan pengendalian intern dalam LAZ maka akan semakin baik pula penerapan good governance dalam LAZ tersebut. Pemanfaatan teknologi informasi berpengaruh positif terhadap penerapan good governance pada LAZ. Semakin baik pemanfaatan teknologi informasi dalam LAZ maka akan semakin baik pula penerapan good governance dalam LAZ tersebut. Terakhir, implementasi total quality management berpengaruh positif terhadap penerapan good governance pada LAZ. Semakin baik pelaksanaan total quality management dalam LAZ maka akan semakin baik pula penerapan good governance dalam LAZ tersebut.

Berdasarkan hasil pembahasan dan kesimpulan di atas, maka peneliti dapat memberikan beberapa saran: pertama, bagi LAZ disarankan untuk meningkatkan implementasi total quality management terkait dengan fokus pelanggan, misalnya peningkatan pelayanan kepada mustahik dan muzaki yaitu dengan mempermudah persyaratan secara administratif untuk menjadi calon mustahik atau muzaki. Kedua, bagi karyawan LAZ disarankan untuk memperbaiki serta meningkatkan cara kerja dalam melayani para calon mustahik maupun muzaki, misalnya seperti bersikap ramah dan santun ketika berhadapan dengan calon mustahik maupun muzaki, menjelaskan secara mendetail kepada para calon mustahik maupun muzaki tentang persyaratan menjadi mustahik maupun muzaki, jika para calon mustahik maupun muzaki mengalami kesulitan terkait dengan informasi LAZ, maka karyawan dengan senang hati memberi tahu dan menjelaskan kepada calon mustahik maupun muzaki tersebut. Ketiga, bagi peneliti selanjutnya disarankan untuk menambah jumlah sampel penelitian yang lebih besar karena jumlah sampel yang lebih besar cenderung kemungkinan besar hasilnya dapat menggambarkan kondisi sesuai dengan kenyataannya serta hasil penelitian memiliki tingkat generalisasi yang lebih tinggi.

Penelitian ini terdapat beberapa keterbatasan, yaitu: pertama, obyek penelitian hanya dilakukan di LAZ saja, sehingga hasil penelitian ini tingkat generalisasinya rendah atau kurang dapat dipublikasikan untuk umum. Kedua, peneliti hanya mengambil sampel sebanyak 42 responden, karena keterbatasan waktu, tenaga dan dana dari peneliti. Ketiga, variabel yang diteliti hanya meliputi pengendalian intern, teknologi informasi, total quality management, dan good governance.

\section{DAFTAR PUSTAKA}

Arifin, Z. 2003. Pengaruh Corporate Governance Terhadap Reaksi Harga dan Volume Perdagangan Pada Saat Pengumuman Earnings. Paper Dipresentasikan pada Simposium Nasional Akuntansi VI, Surabaya.

Efendi, N. 2012. Potensi Zakat Mencapai Rp. 171 Triliun. Artikel ini dimuat dalam website www. pikiran-rakyat.com.

Ekayani, G., dan Zulaekha. 2005. Analisis Kontribusi Nilai Teknologi Informasi Terhadap Kinerja Proses Bisnis dan Dinamika Bersaing (Studi Empiris pada Hotel Berbintang di Bali). Paper Dipresentasikan pada Simposium Nasional Akuntansi VIII, Solo.

Elfara, F. 2010. "COSO". Artikel ini dimuat dalam blog pribadi elrafa.wordpress.com.

Fadillah, S. 2011. Pengaruh Implementasi Pengendalian Intern dan Total Quality Management Terhadap Penerapan Good Governance. Paper Dipresen-tasikan pada Simposium Nasional Akuntansi XIV. Aceh.

Fajri, N. 2012. Potensi Disfungsi Baznas Pasca UU Pengelolaan Zakat. Artikel ini disajikan pada web Forum Zakat(FoZ) www.forumzakat.net.

Juwaini, A. 2011. Mengawal UU Zakat Baru. Artikel ini dimuat dalam website Forum Zakat(FoZ) www.forumzakat.net.

Laten, G. 2012. Partial Least Squares Konsep, Motedo dan Aplikasi Menggunakan Program WarpPLS2.0 Untuk Penelitian Empiris. Semarang: Badan Penerbit Universitas Diponegoro.

Mardiyah dan Listianingsih. 2005. Pengaruh Sistem Pengukuran Kinerja, Sistem Reward, Dan Profit Center Terhadap Hubungan Antara Total Quality Management Dengan Kinerja Manajerial. Paper Dipresentasikan pada Simposium Nasional Akuntansi VIII, Solo.

McKeown, K. R., S. F. Chang, J. Cimino, S. Feiner, C. Friedman, L. Gravano, dan S. Teufel. 2001. PERSIVAL, A System For Personalized Search And Summarization Over Multimedia Healthcare Information. Proceedings of the 1st ACM/IEEE-CS joint conference 
on Digital libraries (pp. 331-340). ACM.

Muhammad, R. 2008. Akuntansi Keuangan Syariah. Yogyakarta: P3El Press.

Mulyadi. 2002. Auditing. Jakarta: Salemba Empat.

Nahaba, B. 2012. Potensi Zakat Bisa Mencapai Rp.300T Per Tahun. Artikel ini dimuat dalam website www.voaindonesia.com.

Natha, K. S. 2008. Total Quality Management Sebagai Perangkat Manajemen Baru Untuk Optimisasi. Buletin Studi Ekonomi.

Nazaruddin, I. Praktik Komputer Statistik. Yogyakarta: Fakultas Ekonomi, Universitas Muhammadiyah Yogyakarta.

Prabowo dan Ariyani. 2005. Investasi Teknologi Informasi dan Kinerja Keuangan: Aplikasi Data Envelopment Analysis (DEA) pada Perusahaan yang Sukses Melakukan Investasi Teknologi Informasi. Paper Dipresentasikan pada Simposium Nasional Akuntansi VIII. Solo.

Pujohar. 2009. Sejarah Pengelolaan ZIS di Indonesia. Artikel ini dimuat dalam website pujohari.wordpress.com

Rama, D. V., dan F. L. Jones. 2008. Sistem Informasi Akuntansi. Jakarta: Salemba Empat.

Suprantiningrum. 2003. Pengaruh Total Quality Management Terhadap Kinerja Manajerial Dengan Sistem Pengukuran Kinerja Dan Sistem Penghargaan (Reward) Sebagai Variabel Moderating (Studi Empiris pada Hotel di Indonesia). Paper Dipresentasikan pada Simposium Nasional Akuntansi VI. Surabaya.

Suwardjono. 2005. Teori Akuntansi Perekayasaan Pelaporan Keuangan. Yogyakarta: BPFE.

Tenner, A. R., I. J. IJ. DeToro .1992. Total Quality Management: The Three Steps to Continuous Improvement. USA: Massachusetts: Addison-Wesley.

Umam, K. 2009. Hukum Ekonomi Islam. Yogyakarta: Instan Lib.

Winidyaningrum dan Rahmawati. 2010. Pengaruh Sumber Daya Manusia dan Pemanfaatan Teknologi Informasi Terhadap Keterandalan Dan Ketepatwaktuan Pelaporan Keuangan Pemerintah Daerha Dengan Variabel Intervening Pengendalian Intern Akuntansi (Studio Empiris di Pemda Subosukawonosraten. Paper Dipresen-tasikan pada Simposium Nasional Akuntansi XIV. Aceh.

Young, A. S., E. Chaney, R. Shoai, L. Bonner, A. N. Cohen, B. Doebbeling, dan R. Perrin. 2007. Information technology to support improved care for chronic illness. Journal of general internal medicine, 22 (3), 425-430. 